\title{
Flow cytometric identification of a minority population of MHC class II positive cells in the normal rat retina distinct from CD $45^{\text {low }} \mathrm{CD} 11 \mathrm{~b} / \mathrm{c}^{+} \mathrm{CD} 4^{\text {low }}$ parenchymal microglia
}

\author{
A D Dick, A L Ford, J V Forrester, J D Sedgwick
}

\begin{abstract}
Aims-This study aimed to isolate and classify by flow cytometry, the cell surface phenotype of microglia in the normal rat retina with a view to identifying putative antigen presenting cells (APC) within the retina, which has to date not been possible by immunohistochemistry.

Methods-Normal rat retinal microglia were isolated and classified using a modification of an isolation technique employing graduated Percoll density gradient cell separation and flow cytometric phenotypic criteria used for CNS microglia.

Results-Retinal microglia can be defined by flow cytometry on the basis of their CD45 ${ }^{\text {low }} \mathrm{CD} 11 \mathrm{~b} / \mathrm{c}^{+} \mathrm{CD} 4^{\text {low }}$ cell surface expression. Constitutive MHC class II expression in the normal rat retina was confined almost exclusively to a very minor population of cells expressing neither low (microglia) nor high levels of CD45. Three colour flow cytometric analysis confirmed that these MHC class II positive cells were $\mathrm{ED2}^{+}$.

Conclusions-Using this sensitive isolation technique we have identified the cell surface characteristics of ramified, resident microglia, and found that they do not constitutively express MHC class II. There is, however, constitutive MHC class II expression on a phenotypically distinct population of cells $\left(\mathrm{CD}_{45^{\text {low/high }}} \mathrm{ED2}^{+}\right)$. We propose these cells are the counterpart of the perivascular macrophages found in the CNS which present antigen to extravasating $T$ cells, although their exact retinal location can only be confirmed by immunohistochemical analysis. The role of parenchymal microglia as APC remains undefined. Future isolation of microglia and putative perivascular cells using this technique will help identify the role these cells play in the initiation and perpetuation of immune responses within the retina.

(Brf Ophthalmol 1995; 79: 834-840)
\end{abstract}

Experimental autoimmune uveoretinitis (EAU) is an established model for auto- immune endogenous posterior uveitis in humans. ${ }^{12}$ This model of intraocular inflammation is mediated by MHC class II restricted $\mathrm{CD4}^{+} \mathrm{T}$ cells which infiltrate the retina early in the course of the disease and, histologically, can be seen entering the retina through both the inner retinal vessels and choroid, ultimately causing destruction of the photoreceptor outer segments where the major uveitogenic antigens are found. ${ }^{1-3}$ Local antigen presentation by MHC class II positive antigen presenting cells (APC) is required to activate systemically primed $\mathrm{CD}^{+}{ }^{+} \mathrm{T}$ cells and initiate the autoimmune inflammatory response. Recently there have been reports of inducible MHC class II antigen expression on non-haemopoietic structural elements within the eye including retinal pigment epithelium, vascular endothelium, and Müller cells. ${ }^{4-6}$ This is analogous to the situation in the CNS where both astrocytes 7 and endothelial cells ${ }^{89}$ can be induced to express MHC class II molecules and process and present protein antigen to $\mathrm{T}$ lymphocytes, at least in vitro (although do not necessarily stimulate the $\mathrm{T}$ cells to divide ${ }^{81011}$ ). However, there is no evidence that any of these cell types function as APC in vivo. ${ }^{12}$ Morphological identification of haemopoietically derived candidate APC within the eye have included the rich network of classic dendritic cells expressing high levels of MHC class II in the choroid ${ }^{13}$ and iris/ciliary body. ${ }^{14}$ The presence of perivascular cuffing in uveitis also argues for the existence of retinal vessel associated APC to enable antigen recognition. However, no such APC has been definitively identified within the rat retina. Thus, to date, the major candidate APC within the rat retina are parenchymal ramified microglia, similar to CNS microglia. These express the CD11b/c molecule, are thought to be bone marrow derived, ${ }^{15}$ but are not MHC class II positive. ${ }^{14}$ In contrast, immunohistochemical analysis of adult human retina has revealed constitutive MHC class II expression on two classes of macrophage lineage cells, expressing low and high levels of the CD45 molecule and representing resident microglia and perivascular macrophage populations respectively, ${ }^{1617}$ analogous to well defined CNS populations in 
Retina
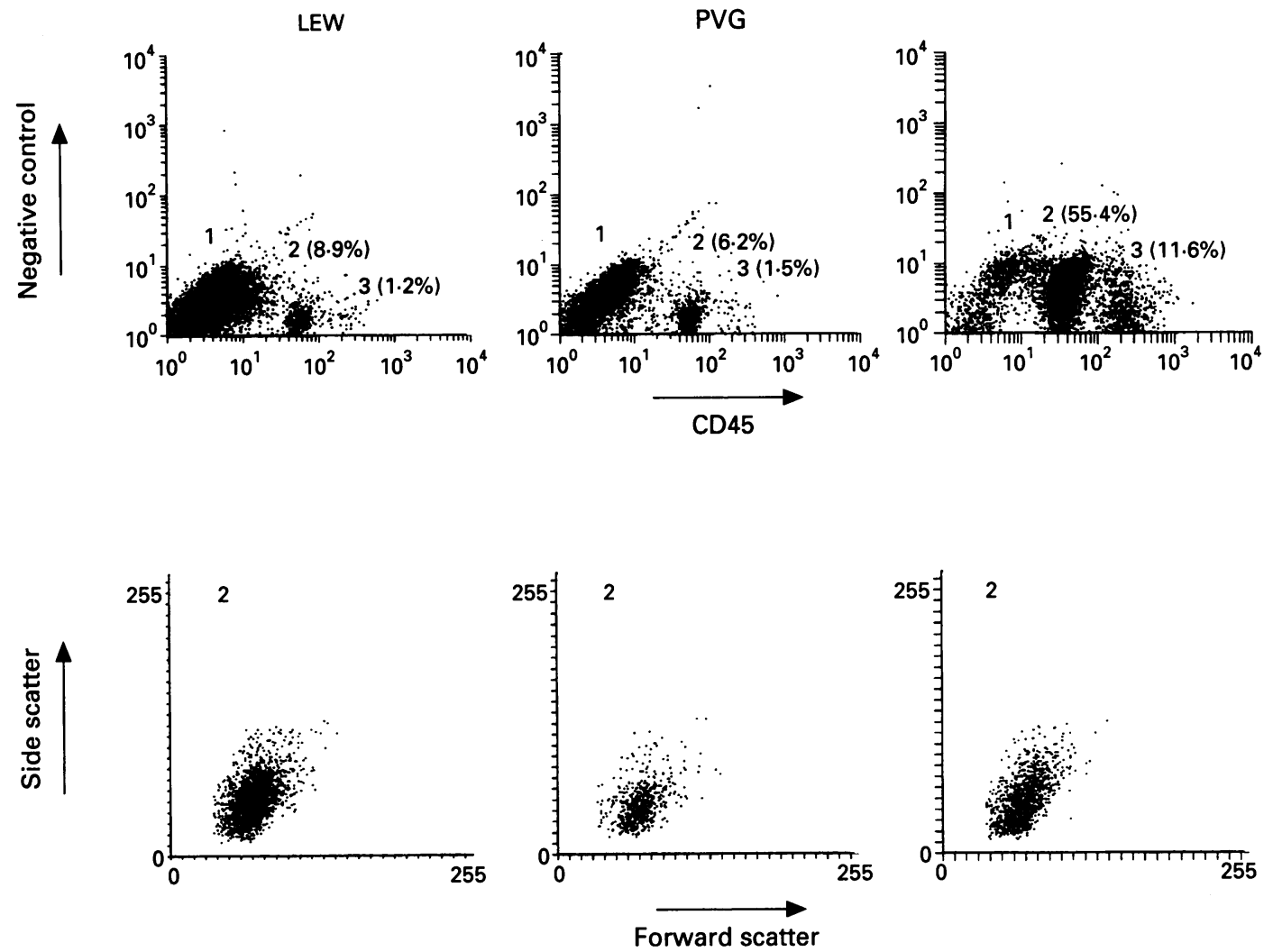

Figure $1 C D 45$ expression and scatter profile of retinal microglia. Labelling of both retinal and CNS preparations with CD $45 \mathrm{mAb}$ subdivides the cells into three main populations $(1-3)$. Number 2 denotes CD45low population (microglia) whose scatter profile seen in the bottom three dot plots is similar for retina (of both LEW and PVG) and CNS preparations.

rat. ${ }^{18} 19$ In the past, not only has immunohistochemistry of the rat retina failed to either distinguish populations of $\mathrm{CD} 45^{+}$cells or demonstrate MHC class II expression but there has been no in vitro or in vivo assessment of the putative APC capacity of human retinal microglia/macrophages. Here we analyse the cell surface phenotype of retinal microglia in the rat by flow cytometry in an attempt to classify putative APC. A minority non-microglial population was identified which has a similar phenotype to CNS perivascular macrophages and is the predominant MHC class II antigen expressing cell within the retina.

\section{Materials and methods}

\section{ANIMALS}

Inbred adult rats of the Lewis (LEW) and PVG strains were obtained from the Animal Resources Centre (Perth, Australia) or bred in local facilities (Blackburn Animal House, University of Sydney). Six-week-old (150$200 \mathrm{~g}$ ) animals were used in the experiments which were conducted according to the code of practice for experiments on animals and guidelines set by the National Health and Medical Research Council (Australia), which adhered to the ARVO statement for the use of animals in ophthalmic and vision research. Each experiment was conducted on two or three rats (four to six retinas) in order to achieve enough cell numbers for flow cytometric analysis and was repeated at least three times except where indicated ( $n$ refers to number of experiments).

PREPARATION OF RETINAL AND CNS MICROGLIA Animals were killed by carbon dioxide asphyxiation then perfused slowly through the left ventricle by intracardiac catheterisation with $250 \mathrm{ml}$ of cold phosphate buffered saline (PBS) with heparin $(250 \mathrm{U})$ to remove circulating mononuclear cells. The retinas from enucleated eyes were microscopically dissected in cold PBS $0.02 \%(\mathrm{w} / \mathrm{v}) /$ bovine serum albumin (BSA) taking care to remove the retina posterior to the ciliary body/pars plana to exclude ciliary body/choroidal contamination, and then disrupted mechanically through a stainless steel sieve. The dissociated material was washed by centrifugation at $400 \times g$ for 10 minutes in $50 \mathrm{ml}$ of PBS/BSA. Subsequent isolation steps were modified from the previously described technique for CNS microglia. ${ }^{18} 19$ In brief, a $2 \mathrm{ml}$ cell suspension of dissociated retinas in PBS/BSA (4-8 $\times 10^{5}$ cells/retina) was added to a graduated Percoll (Pharmacia) gradient prepared in a $10 \mathrm{ml}$ conical bottomed tube. This consisted of $2 \mathrm{ml}$ steps of Percoll at $1.21 \mathrm{~g} / \mathrm{ml}, 1.088 \mathrm{~g} / \mathrm{ml}, 1.072 \mathrm{~g} / \mathrm{ml}$, and $1.03 \mathrm{~g} / \mathrm{ml}$. This gradient was centrifuged at $1250 \times g$ for 20 minutes at $20^{\circ} \mathrm{C}$ with slow acceleration time and no brake. Cells were collected from both the 1.072 and $1.088 \mathrm{~g} / \mathrm{ml}$ layers although the majority of cells were present at $1.072 \mathrm{~g} / \mathrm{ml}$. Viability was determined by trypan blue exclusion after a further wash in PBS/BSA. At this stage $1-2 \times 10^{5}$ cells/retina 
Retina

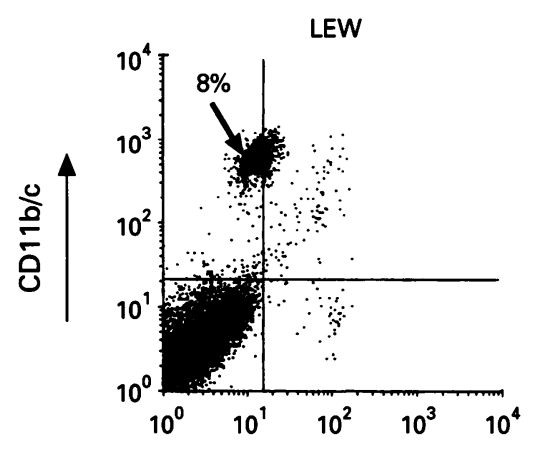

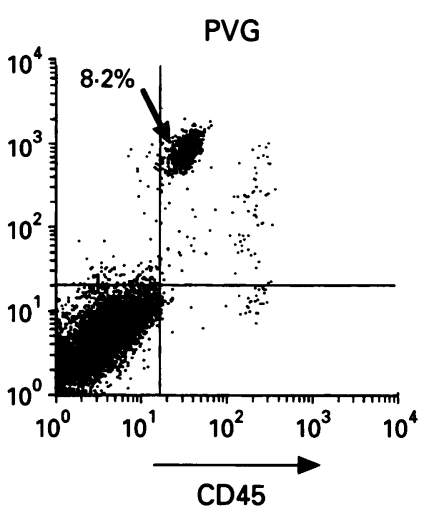

CNS

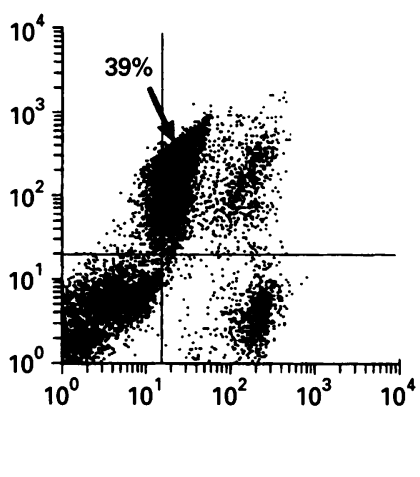

Figure $2 C D 11 \mathrm{~b} / \mathrm{c}^{+}$expression on $C D 45^{\text {low }}$ retinal microglia. Two colour flow cytometric analysis of both retina and CNS showing that the entire CD45low population ( $8 \%$ in retina and $39 \%$ in CNS of gated populations, arrow) express the $C D 11 \mathrm{~b} / \mathrm{c}$ molecule (complement receptor 3/P150-95) known to be present on microglia. This further differentiates the CD45high cell population (population 3, Fig 1) which is split into CD11b/c and CD11b/c cells.

were isolated after density centrifugation for analysis. CNS microglia were isolated as previously described, ${ }^{18} 19$ but only from Lewis strain rats. The significant difference between the CNS and retinal procedures is that the former requires collagenase/DNAse digestion to enhance cell yield and a low density gradient to remove myelin. The non-myelinated retina do not require these steps.

\section{MONOCLONAL ANTIBODIES (MAb) AND FLOW CYTOMETRY}

Mouse mAb specific for rat cell surface markers were originally generated from hybridomas provided by the MRC, Cellular Immunology Unit, Oxford which include MRC OX1 (antiCD45), MRC OX42 (anti-CD11b/c), W3/25 (anti-CD4), MRC OX6 (anti-MHC class II, I-A), MRC OX21 (anti-human C3bi and not rat cells), and R73 (anti- $\alpha \beta$ TCR) from $\mathrm{Dr}$ Thomas Hünig, Würzburg, Germany (see Sedgwick et al ${ }^{18}$ and Ford et al ${ }^{19}$ for cross reference details). ED2 $\mathrm{mAb}^{20}$ was kindly provided by Dr Christine Dijkstra (Amsterdam, the Netherlands). Phycoerythrin (PE) conjugated anti-CD45 was purchased directly from Serotec, UK. mAb MRC OX21 was used as an isotype control for flow cytometry. $\mathrm{mAb}$ were prepared as tissue culture supernatant (TCS) and as ascites (ED2). For direct staining, $\mathrm{mAb}$ were purified and conjugated to biotin or fluorescein isothiocyanate (FITC). TCS mAb was detected with rat absorbed reagent, FITC conjugated sheep $F\left(a b^{\prime}\right)_{2}$ antimouse Ig (Sigma, USA) and biotinylated $\mathrm{mAb}$ were detected either with streptavidin-PE (SA-PE, Caltag, USA) for two colour flow cytometry or streptavidin-Texas Red (SA-TxR, Molecular Probes Inc, USA) for three colour flow cytometry.

Staining was performed as previously detailed $^{18} 19$ using FACS buffer (PBS/BSA/10 $\mathrm{mM} \mathrm{NaN}_{3}$ ) for washes. All reagents, buffers, and incubations were kept and performed at $4^{\circ} \mathrm{C}$. In brief, for two colour labelling a cell suspension of between $10^{4}$ and $10^{5}$ cells was incubated sequentially with TCS $\mathrm{mAb}$ or a 1:50 dilution of ED2 ascites, FITC conjugated sheep $F\left(a b^{\prime}\right)_{2}$ anti-mouse Ig in the presence of $10 \%$ normal rat serum (NRS), blocked with $10 \%$ NRS/normal mouse serum (NMS), biotinylated second $\mathrm{mAb}$ in the presence of both NMS and NRS and finally SA-PE. For three colour labelling, steps were the same except the second $\mathrm{mAb}$ was directly conjugated to $\mathrm{PE}$ (OX1-PE) and biotinylated $\mathrm{mAb}$ were detected with SA-TxR. Cells were fixed with a final $1 \%(\mathrm{v} / \mathrm{v})$ formalin solution and stored at $4^{\circ} \mathrm{C}$ until analysis was performed. Negative controls (identical species and isotype) and single fluorochrome controls were performed to allow accurate breakthrough compensation. Two colour phenotypic analysis of both retina and CNS preparations were performed using FACScan (Becton Dickinson, USA). Three colour phenotypic analysis was performed using a FACStar ${ }^{\text {Plus }}$ sorter (Becton Dickinson, USA) and LYSIS II acquisition and analysis software. A total of 10000 events were collected and both microglial gates and instrument variables were set according to their forward and side scatter characteristics. Analysis of fluorescence was performed after further backgating to exclude dead cells and aggregates. Thus, in most cases, profiles represent less than $50 \%$ of collected events.

\section{Results}

SCATTER PROFILES AND CD45 EXPRESSION

Cells were isolated from the retina of two rat strains, the albino LEW and the PVG. Staining of retinal cells as well as those isolated from the normal LEW rat CNS with an antibody specific for the leucocyte common antigen (CD45) found only on cells of haemopoietic origin, revealed three major populations (top, Fig 1). The characteristic cell surface phenotype of microglia is based on their CD45 expression. ${ }^{18} 19$ There are two populations of CD45 expressing retinal cells; CD45 low microglia (population 2), accounting for $6 \cdot 2-9 \%(n=4)$ of gated cells and CD $45^{\text {high }}$ cells (population 3) accounting for $0 \cdot 6-1 \cdot 9 \%$ of gated cells $(n=4)$. In CNS both these populations are present at a higher percentage of the total and this can be attributed 


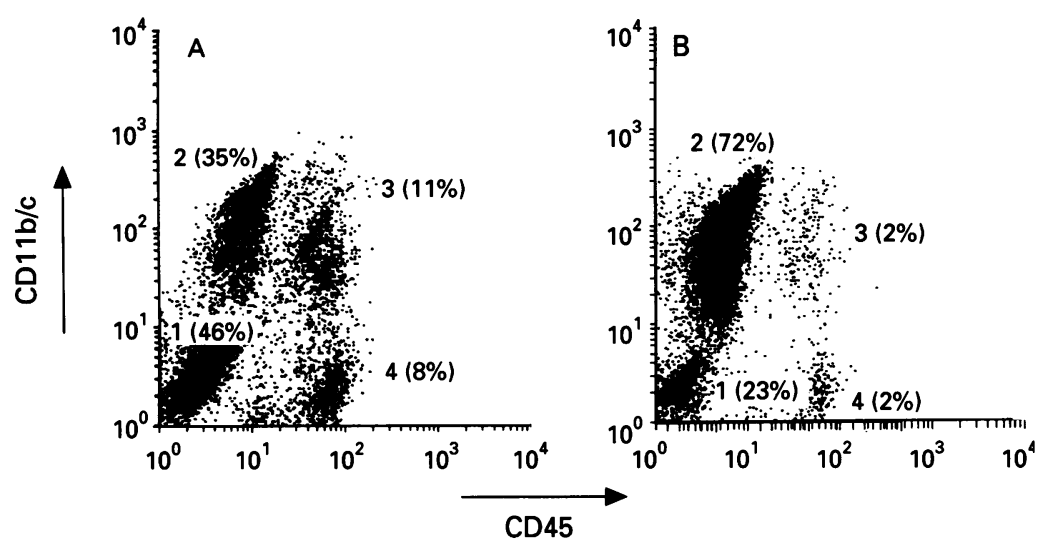

Figure 3 CNS derived CD45 high cells can be proportionally reduced by removal of meninges and choroid plexus. (A) Two colour labelling with CD45 and CD11 b/c of whole CNS preparation reveals a characteristic four population profile (see Fig 2). (B) Analysis of tissue after removal of meninges, tissue dissection away from the ventricles, and then needle biopsies taken from the remaining tissue shows an increase in the microglial yield (population 2) with a corresponding reduction in CD45 high cells (populations 3 and 4). population to the $\mathrm{CD} 45^{\text {high }}$ cells of the retina is difficult to determine and for this reason we have not further characterised their phenotype. Figure 2 also shows that all the CD45 low microglial population are $\mathrm{CD} 11 \mathrm{~b} / \mathrm{c}^{+}$(arrow), a monocyte/granulocyte marker which is known to be expressed by both CNS and retinal microglia. ${ }^{1418} 19$ There was no apparent species difference between LEW and PVG with respect to proportion of cell populations and cell surface phenotype. The slightly different levels of CD45 expression in LEW and PVG retinal microglia represents the use of altered fluorescence gain settings only.

PHENOTYPIC CHARACTERISATION OF RETINAL MICROGLIA

Two colour flow cytometric analysis was used to assess CD4, MHC class II, and ED2 cell surface expression on isolated retinal CD $45^{\text {low }}$ (microglial) and $\mathrm{CD} 45^{\text {high }}$ (mixed) populations. CD4/CD45 staining (Fig 4A) subdivides the populations into four parts (1-4). Population $4\left(\mathrm{CD}_{4} 5^{-}\right)$are $\mathrm{CD}^{-}$as expected. Populations 1-3 which are all $\mathrm{CD}^{+} 5^{+}$are a complex mixture of cells. Microglia (CD45 low, population 3) are $\mathrm{CD} 4^{\text {low }}$ with average $\mathrm{CD} 4$ levels around two times above background. Population 2 is clearly $\mathrm{CD}^{+}$although levels vary, particularly in the CNS, where there is a mixture of $\mathrm{CD}^{+} \mathrm{T}$ lymphocytes $\left(\mathrm{CD} 4^{\text {high }}\right.$, around 20 times above background, arrow) with the remainder being macrophages which express slightly less CD4 (5-6 times above background, arrowhead). Most of population 2 in the retina are also macrophage lineage cells on this basis and $\alpha \beta \mathrm{T}$ cell receptor positive cells are difficult to detect in retinal preparations because of their very low numbers (data not shown). Population 1 is $\mathrm{CD}^{-}$which would include some $\mathrm{CD}^{+} \mathrm{T}$ lymphocytes particularly in the CNS. Flow cytometric analysis reveals a very small population of MHC class $\mathrm{II}^{+}$cells in the retina $(0.36-0.42 \%$ of gated cells, $n=3: R 1$, Fig $4 B$ ) which is substantially less than the equivalent population of cells seen in the whole CNS $(6.3 \%$ of gated cells). In both retina and CNS, MHC class II expressing cells are positioned midway between $\mathrm{CD} 45^{\text {high }}$ and CD45 low populations. In a similar location, a small population of $\mathrm{ED}^{+}$cells $(0.35-0.41 \%$ of gated cells, $n=3)$ have been identified in the retina (R1; Fig 4C) and in the CNS (around $1 \%$ of total). microglia and other associated macrophages already documented for this tissue. ${ }^{18} 19$ In particular, the whole CNS preparation contains relatively higher numbers of CD45 high cells (Fig 1). In both CNS and retinas, this population can be further subdivided into CD11b/c positive (other macrophages) and negative populations (Fig 2). If the CNS is prepared by dissecting frontal lobe away from the ventricles, followed by removal of meninges, including dura mater, arachnoid, and pia mater, and needle biopsy of the remaining tissue the CD45 high population is substantially reduced (Fig 3 ). Whether the remaining CD45 high cells are exclusively perivascular/parenchymal and a parallel

\section{RETINAL MHC CLASS II EXPRESSION IS}

CONFINED TO ED2 ${ }^{+}$CELLS

Constitutive MHC class II expression in the CNS cannot be accounted for by $\mathrm{ED} 2^{+}$cells alone (Figs 4B and C) and in view of the whole CNS preparations used here (see above), this is not surprising. Moreover, published data examining MHC class II expression in the rat CNS at the immunohistological level, indicate that not all $\mathrm{MHC}$ class $\mathrm{II}^{+}$cells are $\mathrm{ED}^{+}{ }^{+22}$ However, the similarity in percentage positive MHC class II and ED2 expressing cells in the retina implied these were the same population. 
A

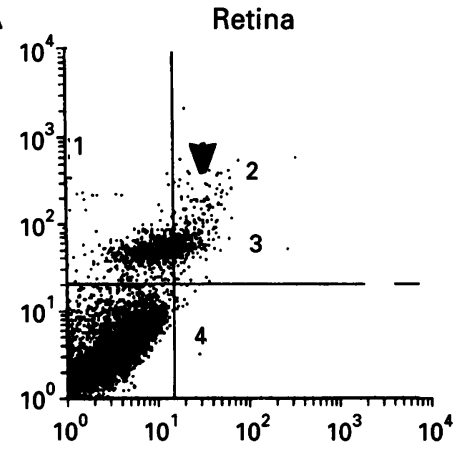

CNS

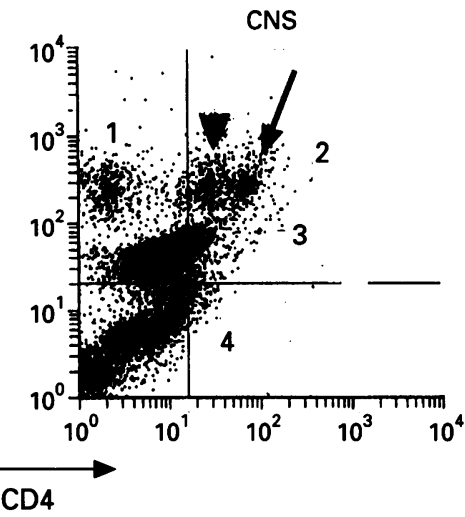

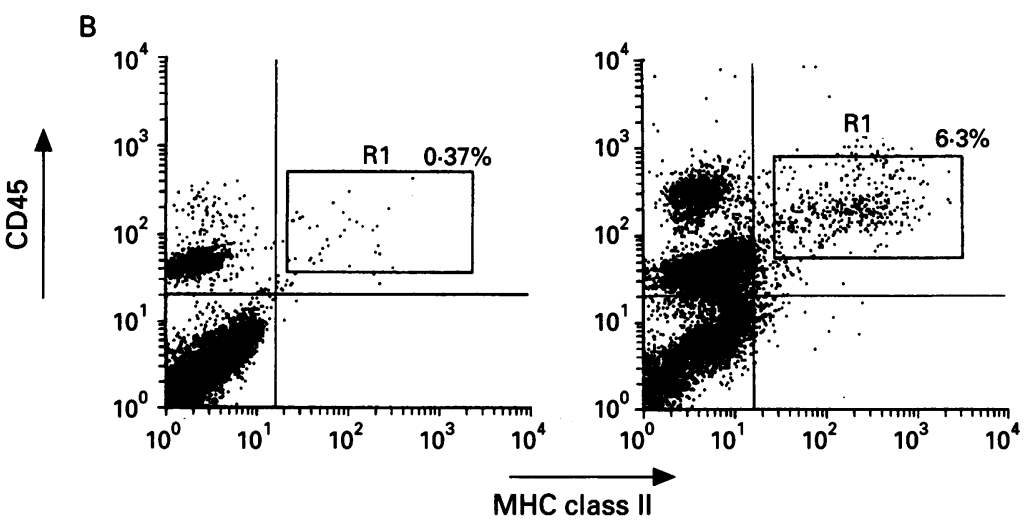

C
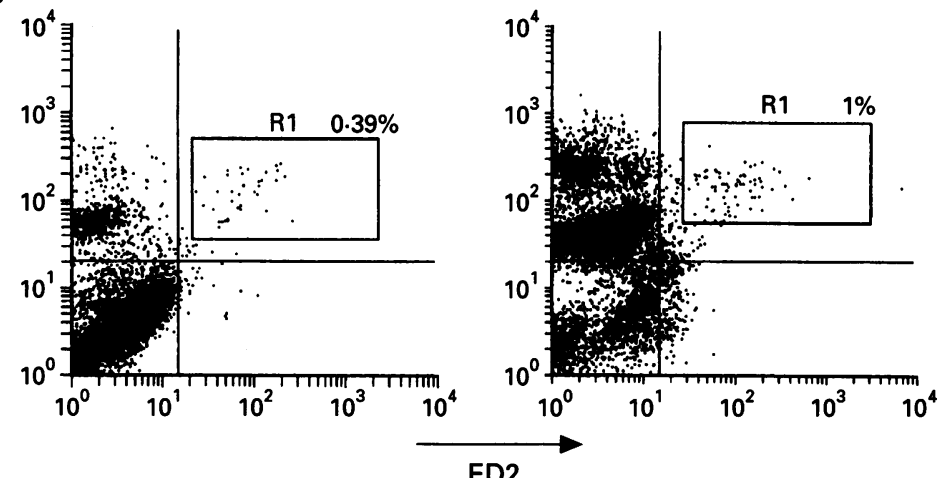

Figure 4 CD4, MHC class II, and ED2 expression on CD45 cells. (A) Population 3 (CD45 ${ }^{\text {low }}$ microglia) are CD4low. The true negative control for this population is exhibited by the negative ED2 staining in $(C)$. Both anti-CD4 and anti-ED2 $m A b$ are of the mouse IgG1 isotype. Thus the shift of population 3 to the right in $(A)$ is real. Population 2 contains some $\mathrm{CD4}^{+} \mathrm{T}$ cells in the CNS (arrow) with the remainder being macrophages (arrowhead). The $C D 45^{-}$population 4 are $C D 4^{-}(B)$ and $(C)$. Minor populations of cells (R1) which are $C D 45^{+} \mathrm{MHC}$ class $\mathrm{II}^{+}$and $C D 45^{+} E D 2^{+}$respectively.

To confirm this, three colour flow cytometry was required and the results of this are shown in Figure 5 . By gating around $\mathrm{CD} 45^{+} \mathrm{ED} 2^{+}$or $\mathrm{CD} 45^{+} \mathrm{ED} 2^{-}$populations and then assessing these for MHC class II expression it is clear that the majority $(>85 \%)$ of ED2 ${ }^{+}$cells are MHC class $\mathrm{II}^{+}$while few, if any of the ED2cells are. The latter includes all microglia.

Substantial MHC class II expression is found in the uvea of the eye. ${ }^{1314}$ Contamination of retinal preparations by this tissue can be excluded as follows: (1) retina was carefully dissected posterior to the ciliary body and also a frill of retina was left around the optic nerve head preventing choroidal seeding when the retina was removed. (2) The retina was easily identified, particularly in the pigmented

PVG, as separate from the choroid because of the presence of retinal pigment epithelium. (3) Choroidal MHC class $\mathrm{II}^{+}$cells are, in the majority ED2 negative, ${ }^{13}$ a phenotype we did not identify in the pure retinal preparations.

\section{Discussion}

The eye has been considered an immune privileged site because of the lack of dedicated lymphatics and the absence of professional APC. With the recent evidence that the uvea has cells which at least morphologically and phenotypically resemble cells known to act as competent APC, 131421 the question arises as to whether the retina itself contains any immunocompetent cells which may play a role in the inflamed retina. We have defined by flow cytometric analysis, rat retinal microglia which have markers in common with haemopoietic derived cells, in particular, CD45 and CD11b/c. This resident microglial population has a similar phenotype $\left(\mathrm{CD} 45^{\text {low }} \mathrm{CD} 11 \mathrm{~b} / \mathrm{c}^{+} \mathrm{CD} 4^{\text {low }}\right)$ to CNS microglia. ${ }^{18} 19$ Retinal microglia can be distinguished from another minor population of cells within the rat which have not been previously described and these express the ED2 marker ${ }^{20}$ and intermediate levels of CD45 (CD45 low/high). Most significantly, three colour flow cytometric analysis provided unequivocal evidence that the majority of retinal ED2 ${ }^{+}$cells are $\mathrm{MHC}$ class $\mathrm{II}^{+}$, clearly distinguishing them from $\mathrm{ED}^{+}$cells in the adjacent choroid where most are MHC class II negative. ${ }^{13}$ Retinal derived ED2 ${ }^{+}$cells account for almost all the MHC class II staining in the normal rat retina.

Two aspects are of note. Firstly, the ED2 ${ }^{+}$ cell population is present at a rate of approximately 1:250 cells, and this assumes an equal efficiency of isolation of all cell types. In fact, it is likely that highly processed cells including Müller cells and many neuronal elements may be isolated with lower efficiency, so the 1:250 frequency is probably an overestimate. Thus, the paucity of ED2 ${ }^{+}$cells may account for the documented absence of MHC class II staining in retina by immunohistochemistry, a technique $^{1314}$ which is unable to sample entire tissue as we have done here. Secondly, previous reports on isolation, phenotype, and culture of microglia from the CNS and retina which have proposed the microglia as a candidate APC within these tissues have used markers to define the microglial population (for example, CD11b) which are also shared by some peripheral blood leucocytes as well as the minority perivascular cell population. It is clearly difficult to distinguish between resident microglial cells (parenchymal), perivascular cells, other associated macrophages, and those cells infiltrating from the blood by means other than flow cytometry.

The animal model of posterior uveitis, EAU, demonstrates cells which enter the retina from the choroid, where a large inflammatory response is seen and also the inner retinal vessels where large perivascular cuffs develop. The severity of choroiditis and inner retinal vasculitis varies with type and dose of 


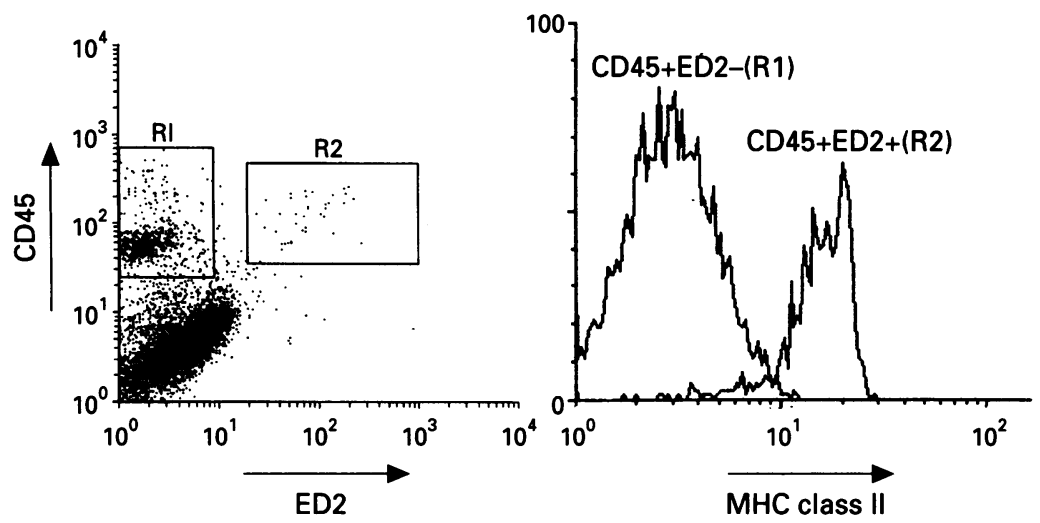

Figure 5 Most constitutive MHC class II expression in the normal retina is on ED2 ${ }^{+}$ cells. Retinal cells were stained for three colour flow cytometry for the markers CD45, ED2, and $\mathrm{MHC}$ class II. The dot plot (left) is a representative example of expression of ED2 versus $C D 45$ by two colour flow cytometry. The $M H C$ class II expression of two populations, $R 1\left(C D 45^{+} E D 2^{-}\right)$and $R 2\left(C D 45^{+} E D 2^{+}\right)$was assessed by forming analysis regions as shown. cells are relatively poor APC for secondary T cell responses compared with other nonmicroglial CNS macrophages. ${ }^{19}$ The latter may include at least some of the perivascular cell populations. Finally, the range of CD4 expressing cells in rats and humans appears comparable, unlike mice, in that both express the CD4 antigen on cells of the macrophage monocyte lineage. ${ }^{2627}$ Thus the finding of CD4 expression in both the perivascular and microglial populations of the retina, though at a lower level than CD4 expression of $\mathrm{T}$ cells (Fig 4), suggests that comparable cells in humans may be targets of human immunodeficiency virus (HIV) infection in the retina, similar to the CD4 dependent HIV infection on CNS microglia. ${ }^{28}$

The authors would like to thank Joseph Webster and Patrick Taylor for their technical assistance with the FACStar Plus Karen Knight and her team for breeding and care of experimental animals, and especially Anna Goodsall for producing and titrating monoclonal and polyclonal antibodies used in this study. We would also like to thank Dr Paul McMenamin for helpful discussions. The studies were supported by grants to JDS from the National Health and Medical Research Council, JDS from the National Health and Medical Research Council,
the Multiple Sclerosis Society of Australia, Commonwealth the Multiple Sclerosis Society of Australia, Commonwealth
AIDS Research Grants and to ADD from the Leverhulme AIDS Research Grants and to ADD from the Leverhulme
Trust, UK. A D Dick is a Wernher-Pigott MRC travelling Trust, UK. A D Dick is a Wernher-Pigott MRC travelling
fellow, J D Sedgwick is supported by a Wellcome Trust senior research fellowship in medical sciences in Australia, and $\mathrm{J} \mathrm{V}$ Forrester is supported by Guide Dogs for the Blind, UK. reach the choroid, but as yet no cell has been identified which may act as an APC for T cells which have entered the retina through the inner retinal vessels. We have shown that a small population of $\mathrm{MHC}$ class $\mathrm{II}^{+}$cells are present in perfused retinal preparations of both LEW and PVG rats and that these cells in the retina are confined to the $\mathrm{ED}^{+}$phenotype. We propose these are the counterpart of the perivascular cell (or perivascular macrophage) found in the CNS, 1222 although their location can only be confirmed by immunohistochemical analysis. Studies in irradiation chimeric rats have shown that such perivascular cells can present autoantigen to $T$ cells in vivo, ${ }^{23}$ and it is likely the ED2 ${ }^{+}$cells detected here may similarly act as APC within the retina. Nevertheless it remains for us to isolate $\mathrm{ED}^{+}{ }^{+}$cells as well as retinal microglia to establish their APC role. Such studies are obviously difficult given the small numbers of cells involved but are currently being attempted.

Our findings are at least in part, consistent with previous immunohistochemical studies in adult human retina ${ }^{1617}$ which have demonstrated MHC class $\mathrm{II}^{+}$perivascular cells. Unlike human retina, however, we could not identify in rat, any pronounced MHC class II expression on resident microglia. Retinal microglia have been implicated in inducing phagocytic, cellular, and vascular changes in dystrophic retina and also have phagocytic capacity within the subretinal space during development. ${ }^{24} 25$ Their role as professional APC and in immunoregulation has yet to be defined but flow cytometric analysis can identify and has the potential to then isolate cell populations for further study. Although upregulation of MHC class II expression on microglia occurs in the inflamed rat retina (J V Forrester, unpublished data) as it does in the CNS, ${ }^{18}$ our recent studies with freshly isolated microglia from rat CNS indicate these
1 Gery I, Mochizuki M, Nussenblatt RB. Retinal antigens and the immunopathologic process they provoke. Prog Ret Res 1986; 5: 75-109.

2 Forrester JV, Liversidge J, Dua HS, Towler $H$, McMenamin PG. Comparison of clinical and experimental uveitis. Curr Eye Res 1990; 9: 75-84.

3 Caspi RR, Roberge FG, Mcallister CG, El-Said M, Kuwabara T, Gery I, et al. T-cell lines mediating experi-
Ri mental autoimmune uvoretinitis (EAU) in the rat. f Immunol 1986; 136: 928-33.

4 Liversidge J, Sewell HF, Forrester JV. Interactions between lymphocytes and cells of the blood retinal barrier: mechanisms of $\mathrm{T}$-lymphocyte adhesion to human retinal capillary endothelial cells and retinal pigment epithelial cells in vitro. Immunology 1990; 71: 390-6.

5 Chan CC, Hooks JJ, Nussenblatt RB, Detrick B. Expression of Ia antigen on retinal pigment epithelium in experimental autoimmune uveoretinitis. Curr Eye Res 1986; 5: tal autoim 32 .

6 Roberge FG, Caspi RR, Nussenblatt RB. Retinal Muller cells produce IL-1 activity and have a dual effect on autoimmune T-helper lymphocytes. F Immunol 1988; 140: 2193-9.

7 Fontana A, Fierz W, Wekerle H. Astrocytes present myelin basic protein to encephalitogenic T-cell lines. Nature

8 Pryce G, Male D, Sedgwick J. Antigen presentation in brain: brain endothelial cells are poor stimulators of $\mathrm{T}$ cell proliferation. Immunology 1989; 66: 207-12.

9 Fabry Z, Sandor M, Gajewski TF, Herlein JA, Waldscmidt $M M$, Lynch RG, et al. Differential activation of Th1 and Th2 CD4+ cells by murine brain microvessel endothelial cells and smooth muscle/pericytes. F Immunol 1993; 151: 38-43.

10 Risau W, Engelhardt B, Wekerle H. Immune function of the blood-brain barrier: incomplete presentation of protein (auto-)antigens by rat brain microvascular endothelium in vitro. F Cell Biol 1990; 110: 1757-64.

11 Fabry Z, Waldschmidt MM, Moore SA, Hart MN. Antigen presentation by brain microvessel smooth muscle and presentation by brain microvessel smooth m.

12 Sedgwick JD, Hickey WF. Antigen presentation in the central nervous system. In: Keane RW, Hickey WF, eds. Immunology of the nervous system. Oxford: Oxford University Press, 1995

13 Forrester JV, McMenamin PG, Holthouse I, Lumsden L, Liversidge J. Localisation and characterisation of major histocompatibility complex class II-positive cells in the autoimmune uveoretinitis. Invest Ophthalmol Vis Sci 1994; 35: 64-77.

14 McMenamin PG, Holthouse I, Holt PG. Class II major histocompatability complex (Ia) antigen bearing dendritic cells in the iris and ciliary body of the rat eye: distribution, cells in the iris and comition phenotype and re

15 Perry VH, Gordon S. Macrophages and microglia in the nervous system. Trends Neurosci 1988; 11: 273-7.

16 Penfold PL, Provis JM, Liew SCK. Human retinal microglia express phenotypic characteristics in common with dendritic antigen-presenting cells. $\mathcal{f}$ Neuroimmunol 1993; 45: 183-92. 1984; 307: 273-6. posterior segment of the eye: implications for induction of 
17 Penfold PL, Madigan MC, Provis JM. Antibodies to human leukocyte antigens indicate subpopulations of microglia in human retina. Vis Neurosci 1991; 7: 383-8.

18 Sedgwick JD, Schwender S, Imrich H, Dorries R, Butcher $\mathrm{GW}$, ter Meulen V. Isolation and direct characterisation of resident microglial cells from the normal and inflamed central nervous system. Proc Natl Acad Sci USA 1991; 88: 7438-42.

19 Ford AL, Goodsall AL, Hickey WF, Sedgwick JD. Norma adult ramified microglia separated from other CNS macrophages by flow cytometric sorting: phenotypic differences defined and direct ex vivo antigen presentation to myelin basic protein-reactive $\mathrm{CD4}^{+} \mathrm{T}$ cells compared. fImmunol (in press).

20 Dijkstra CD, Dopp EA, Joling P, Kraal G. The heterogeneity of mononuclear phagocytes in lymphoid organs: distinct macrophage subpopulations in the rat recognised by monoclonal antibodies ED1, ED2 and ED3 Immunology 1985; 54: 589-96.

21 McMenamin PG, Crewe J, Morrison S, Holt PG Immunomorphologic studies of macrophages and MHC class II + dendritic cells in the iris and ciliary body of the rat, mouse and human eye. Invest Ophthalmol Vis $\mathrm{Sci}$ 1994; 35: 3234-50.
22 Streit WF, Graeber MB. Heterogeneity of microglial and perivascular cell populations: insights gained from the perivascular cell populations: insights gained

23 Hickey WF, Kimura H. Perivascular microglial cells of the CNS are bone marrow-derived and present antigen in vivo. Science 1988; 239: 290-2.

24 Thanos S. Sick photoreceptors attract activated microglia from the ganglion cell layer: a model to study the inflammatory cascades in rats with inherited retinal dystrophy. Brain Res 1992; 588: 21-8.

25 Loffler K, McMenamin PG. Evaluation of subretinal macrophage-like cells in the human fetal eye. Invest Ophthalmol Vis Sci 1990; 31: 1628-35.

26 Jeffries WA, Green JR, Williams AF. Authentic T helper CD4 (W3/25) antigen on rat peritoneal macrophages.

27 Fxp Med 1985, 162: 117-27.

antibodies react with cells of antibodies react with cells of monocyte-macrophage
and Langerhans lineage. $\mathcal{f}$ Immunol 1983; 131: 212-7

28 Jordan CA, Watkins BA, Kufta C, Dubois-Dalcq $M$. Infection of brain microglial cells by human immunodefciency virus type I is CD4-dependent. $\mathcal{F}$ Virol 1991; 65: 736-42. 